so Rall, W., and Shepherd, G. M., J. Neurophysiol., 31, 884 (1968). ${ }^{31}$ Adey, W. R., Neurosciences Res. Program Bull., 7., No. 2, 75 (1969). 32 Gardner, R. A., and Gardner, B. T., Science, 165, 664 (1969). ${ }^{33}$ Premack, D., J. Exp. Anal. Behav., 14, 107 (1970).

${ }^{34}$ Ploog, D., and Melnechuk, T., Are Apes Capable of Language? Neurosciences Res. Program Bull. (in the press).

\author{
${ }^{35}$ Delgado, J. M. R., Physical Control of the Mind: Toward a Psychocivilized \\ Society, World Perspectives, 41 (Harper and Row, New York, 1969). \\ ${ }^{36}$ Sweet, W. H., Ervin, F. T., and Mark, V. H., Aggressive Behavior (edit. by \\ Sweet, W. H., Ervin, F. T., and Mark, V. H., Aggressive Behavior
Garattini, E. B.), 336 (Excerpta Medica, Amsterdam, 1969). \\ Dobbing, J., New Scientist, 46, 636 (1970).
}

ss 'Taylor, A., Amer. J. Orthopsychiat., 38, 835 (1968).

\title{
Second Golden Age of Molecular Biology
}

The highlights of a year when microorganisms have proved more productive than ever for studying the genetic apparatus of cells have been the isolation and synthesis of DNA genes and the sequencing

by of RNA phage genes. First steps have been taken towards characterizing the enzymes which synthesize DNA and degrade RNA in bacterial cells. Protein synthesis in mammals is initiated in a way similar to bacteria; this supports the idea that the mechanisms of heredity are universal even in their details. A breakthrough in understanding the action of RNA tumour viruses has been the finding that they reverse the central dogma of molecular biology by directing synthesis of DNA.
A YEAR or so ago it was fashionable to say that the golden age of molecular biology had come to an end ${ }^{1}$ and that research should now concentrate in other areas, such as genetic differentiation or neurobiology. But the advances of the past year have shown only too clearly that "classical" molecular biology cannot be disposed of so readily. Certainly, it is true that much of its conceptual framework is now firmly established and is unlikely to be overturned ${ }^{2}$; but after passing through a comparative plateau of discovery, bacterial protein and nucleic acid synthesis is turning out to be rather more complex than it seemed; and extension to higher organisms, and to their viruses, of the approaches used with bacteria is at last beginning to pay dividends.

Although there is now a depressing proliferation of control systems - it seems that one has only to think of a control system to find that it is used somewhere-the idea that there is a basic similarity between all organisms in at least their mechanisms of protein and nucleic acid synthesis is taking an increasing hold on the direction of research. Armed with a detailed knowledge of how proteins aro synthosized in Escherichia coli, many research teams are looking to see whether the samo processes work in more complicated organisms.

The most striking similarities are those between the various protein factors required for protein synthesis; in addition to the protein components of the ribosome itself, at least eight factors associate with it at particular stages of protein synthesis. The three factors concerned with the elongation of the growing polypeptide chain have been known for some time to fulfil closely related functions in $E$. coli, yeast, reticulocytes and rat liver. Factors to assist the termination of protein synthesis have so far been found only in $E$. coli, but there is no reason to suppose that, when found, they will prove to be much different in other organisms.

\section{Initiation of Protein Synthesis}

Despair that protein synthesis may start in different ways in different systems arose from tho suggestion that $\mathrm{N}$-acetyl-valine can initiate haemoglobin synthesis in vitro $^{3}$, and that histones may start with $\mathrm{N}$-acetyl-serine ${ }^{4}$; for in $E$. coli, protein synthesis is initiated only by $\mathrm{N}$-formylmethionine. An AUG codon at the beginning of a gene codes for formylmethionyl-tRNA; this is a methionyl-tRNA in which the free amino group of the amino-acid has been blocked by addition of a formyl group. E. coli cells also possess another type of methionine accepting tRNA (tRNA ${ }_{\mathrm{m}}^{\mathrm{Met}}$ ), which cannot be formylated and which is used to provide methionine residues within proteins. For $E$. coli proteins which cornmence with methionine, the formyl group is subsequently removed from the nascent protein by a specific enzyme; and for proteins which commence with other amino-acids, the terminal methionine is also removed to reveal the proper $\mathrm{N}$-terminal amino-acid ${ }^{2}$.

Hopes that most proteins may after all start in the same way have been revived by the finding at the MRC laboratory in Cambridge that mouse ascites tumour and liver cells contain two methionine tRNAs, one of which can be formylated in vitro by the $E$. coli transformylase enzyme, and the other of which cannot ${ }^{5}$. The formylatable species places methionine at the $\mathrm{N}$-terminal end of proteins, and the non-formylatable species provides methionine for internal sitos ${ }^{6}$. But although the two mouse mothionine tRNAs seem to play roles analogous to those of $E$. coli, neither is formylated in vivo. The ability of the initiator Met-tRNA to be formylated may therefore be an evolutionary hangover.

Haemoglobin also seems to be initiated in a manner similar to bacterial proteins. Both the $\alpha$ and $\beta$ chains of rabbit globin are initiated with a methionine residue which is removed during the early stages of polypeptide chain growth to reveal the physiological $\mathrm{N}$-terminal amino-acid, valine? ${ }^{7}$ As a similar mechanism initiates the synthesis of protamines (basic proteins) in trout testis cells ${ }^{8}$, this form of initiation may be in general use.

One problem raised by the existence of two types of methionine tRNA, each of which responds to the same codon (AUG), is how only the initiator tRNA rosponds to those AUG codons at the beginning of genes, but the internal coding tRNA responds within the message. In $E$. coli, the elongation factors which transfer tRNA to the ribosome recognize all normal aminoacyl-tRNAs, but do not interact with the initiator formylmethionyltRNA . Conversely, the factors involved in initiation bind only the initiator tRNA and no other aminoacyltRNA. Reticulocytes probably have a similar mechanism, for their initiation factors preferentially bind initiator Met-tRNA and their elongation factors discriminate against this $\mathrm{tRNA}^{9}$.

Ribosomes also must be able to distinguish AUG initiator codons from AUG triplets within messengers, 
perhaps by recognizing some nucleotide sequence somewhat longer than the AUG codon itself. The most promising approach to resolving the dilemma of the ribosome in deciding the meaning of AUG codons has come from the sequencing of RNA phages. The $\mathrm{f} 2$ phages have as their genetic material a molecule of RNA some 3,500 nucleotides long which comprises three genes; these code for maturation protein, coat protein and an RNA replicase which reproduces the phage. More than 500 residues have been sequenced during the past year, including the regions at each end of the RNA molecule, the initiation regions at the beginning of each of the three genes, the termination region of the coat protein gene, and also a considerable proportion of the internal region of this gene.

The initiation regions of the three genes have been characterized by allowing ribosomes to bind to the RNA phage to form an initiation complex. Treatment with nuclease then destroys the RNA molecule, except for the initiation sequences, which are protected by the ribosome binding ${ }^{10}$. All the initiation sequences have an AUG codon, and curiously, all also have a UGA termination codon in phase a few triplets before the initiator codon. But there seems to be no extensive similarity in the sequences bound to the ribosome. This means that there nay be more than one type of ribosome recognition sequence on a messenger, and this could act as a control over its translation.

The chain termination sequence of the coat protein gene contains two different terminator codons in immediate succession, UAA UAG ${ }^{11}$. The general significance of this redundancy is not clear, but the proper termination of proteins may bo so important that this is a precaution against the suppression of termination that takes place when ecrtain tRNAs are mutated so as to recognize nonsense codons instead of their proper codons.

An intriguing result of the sequeneing is that there seem to be large stretches of the phage that are not translated into protein. As well as regions at each end of the phage (at least the first 100 nucleotides at the $5^{\prime}$ end, and at least the last 50 at the $3^{\prime}$ end) which do not code for protein, there are untranslated sequences separating the genes. Phage $Q \beta$, an RNA phage unrelated to the $\mathrm{f} 2$ group, also has a long (175 nucleotides) untranslated $5^{\prime}$ terminal region ${ }^{12}$. So far as can be judged from the sequences now known, the $\mathrm{f} 2$ phages have an extensively ordered secondary structure with many hairpin loops. Although it may be somewhat easier to discover their functions when the complete phage sequence is known, one possible role for the untranslated rcgions and secondary loops may be to control the translation of the phage RNA into protein (see Nature, 226, 1093; 1970). In spite of some speculation, however, there is no reason to suppose that this sort of control mechanism also applies to bacterial messengers.

\section{Control of RNA Synthesis}

Protein factors are making their presence felt in virtually every area of molecular biology. Until very recently, almost all that could be said about the mechanism of RNA transcription was that it is catalysed by the enzyme RNA polymerase. But it is now elear that although the basic enzymo possesses the catalytic activity which synthesizes phosphodiester bonds, the initiation and termination of transcription are assisted by protein factors. The precise role which the termination factor, rho ${ }^{13}$, plays in vivo is muddled at present, for in vitro, at any rate, there is more than one way in which RNA synthesis can be terminated (see Nature, 226, 1093; 1970).

The RNA polymerase of $E$. coli is a multimeric protein, one subunit of which, the sigma factor, is concerned with the initiation of RNA synthesis. The sigma factor is released from tho RNA polymerase-DNA complex as soon as synthesis of the RNA chain has begun, learing the task of transcribing DNA into RNA to the remaining subunit complex, the core enzyme ${ }^{2}$. It is the sigma. factor which determines the specificity of transcription; the core enzyme by itself can use DNA as template for the transcription of RNA, but does so by transeribing only random segments of the genome. When the sigma factor is present, by contrast, transcription takes place only from certain starting points (promotors) ${ }^{14}$.

But the role of sigma extends beyond merely restricting the core enzyme to transcribing certain bacterial genes, for more than one such factor has been identified. It is true that there is only one sigma factor in bacteria, but the production of further such factors plays an important role in bacteriophage infection. When a $\mathrm{T} 4$ bacteriophage infects an $E$. coli cell, only certain parts of its genome (the immediate early genes) are transcribed. This is because the $E$. coli sigma factor recognizes only their promotors ${ }^{15}$.

One of the first proteins synthesized after phage infection is another sigma-like factor, which displaces the bacterial factor and directs the core enzyme of the host cell to synthesize RNA from a different set of bacteriophage genes (the delayed early genes) ${ }^{16}$. During infection, some of the subunits of the host enzyme are mcdified; although this does not affect which carly genes aro transcribed, one function of this modification may be to change the affinity of the core enzyme for sigma-like factors, so that later in infection it associates with a second phage-coded sigma-like factor; the production of this sigma factor results in transcription of another set of bacteriophage genes (the late genes) (see Nature, 226, $1093 ; 1970)$.

\section{Killer Ribosomes}

Bacterial messenger RNAs are uotorionsly unstable, with half lives of a few minutes only. But although a good deal is known about the synthesis and translation of mRNA, it has proved more difficult to characterize the enzyme(s) which must be responsible for its degrada. tion. Almost all that is known for sure about messenger brcakdown is that the degradation of a messenger seons to follow, as it were, the tightly packed cluster of ribo. somes which translates the message. As the ribosumes themselves follow closely after the RNA polymerese which is synthesizing the messenger, this means that degradation at one end begins even before the far end has been synthesized ${ }^{2}$.

Many ribonucleases have been found in $E$. coli, but that responsible for degrading messengers has remained remarkably elusive. 'The fifth ribonucleast' to be found (ribonuclease V), however, has at least some of the required properties ${ }^{17}$. This enzyme seems to be part of the ribosome and degrades mRNA from $5^{\prime}$ to $3^{\prime}$ in a sequential manner; it is specific for mRNA and does not attack rRNA. The enzyme activity requires all the components necessary for the movement of ribosomes along messengers and is inhibited by inhibitors of protein synthesis. This may mean that some fixed proportion of ribosomes contains this enzyme, and when one of these "killer" ribosomes attaches to the message, it degrades 
the mRNA as it moves along at the end of the cluster of ribosomes.

But the isolation of what may be a mutant in a messenger-endonuclease lends credence to the idea that the degradation of mRNA may not always be as simple a process as the molecular biologist would hope. The existence of this enzyme has been inferred from the finding of a mutant which relieves polarity in $E$. coli. Polarity is the term coined to describe the observation that a nonsense mutant in one gene of a bacterial operon may have two effects; as well as inactivating the protein coded by the gene in which it occurs, it may also cause a reduction in the amount of (normal) protein(s) synthesized by genes subsequent to that mutated ${ }^{2}$. Although polarity is at least partly caused by the reduced translation of the portions of the polycistronic messenger beyond the nonsense codon (presumably because the ribosome dissociates from the mossage at the nonsense site), transcription may also be affected. The messenger representing the opcron in such cases is smaller than usual because it lacks the segment corresponding to the part of the operon beyond the mutant site. Two explanations have been proposed to account for this; transcription as well as translation may for some reason come to an untimely end at the nonsense codon so that the distant part of the messenger is never synthesized; or this part of the messenger may be synthesized, but is broken down so fast by nuclease action that it is not available for translation.

The distant part of the messenger might be defenceless before the onslaught of the nucleases because the ribosomes which would protect it from such an attack have dissociated from it at the nonsense mutant site. This theory would require an endonuclease to be involved in messenger degradation, because the first section of the mRNA would be protected by the ribosomes translating it. Support for this idea comes from the finding of a mutant of $E$. coli in which polarity is generally relieved; in the tryptophan operon, at least, this relief is associated with the reappearance of the messenger corresponding to the distant parts of the message ${ }^{18}$. This could be explained if the mutant had an inactive messenger-endonuclease. After the message had been cleaved internally by the endonuclease, a second enzyme could degrade the fragments released; this enzyme would not need to work in the $5^{\prime}$ to $3^{\prime}$ direction, but could perhaps work backwards from the site of cleavage in a $3^{\prime}$ to $5^{\prime}$ direction.

\section{Elusive Replicating Enzymes}

The most central issue of molecular biology is perhaps that of how the genetic material is replicated. A good deal is known about the mode of DNA replication ${ }^{2}$; it is semi-conservative (probably taking place by unwinding of the two parental strands, each of which then synthesizes a complementary strand by base pairing); the accuracy of the process does not depend entirely on the specificity of hydrogen bonding between base pairs but is to some extent influenced by the replicating enzyme(s); it is discontinuous, each of the new DNA strands being made in short fragments which are only subsequently covalently linked together.

But although some of the ancillary enzymes and genes involved in replication have been identified (such as the polynucleotide ligase which joins together the discontinuous segments), the enzyme(s) which actually replicate the DNA remain elusive. The Kornberg DNA polymerase, long hailed as the replicating enzyme, will, it is true, replicate DNA in vitro, but the manner in which it does so does not support the idea that it replicates DNA in vivo. This enzyme prefers single stranded DNA as template, and does not work well when duplex DNA is its substrate.

Suspicions that the Kornberg enzyme may be concerned with the repair of damaged DNA in the coll and not with replication have hardened with the characterization of the many catalytic activities which it can undertake in vitro ${ }^{19}$, and with the isolation of a mutant of $E$. coli which lacks the enzyme activity when assayed in vitro. DNA polymerase can not only synthesize DNA in vitro, but can also hydrolyse the strands of a DNA duplex in either direction, or can instead use pyrophosphato ions to achieve pyrophosphorolysis in a $5^{\prime}$ to $3^{\prime}$ direction. Even more significant, DNA polymerase can excise thymine dimers from DNA in vitro (the covalent linking of adjacent thymines into a dimer is the major result of ultraviolet irradiation of cells) by releasing them into the cell supernatant in oligonucleotide fragments ${ }^{20}$. Clearly, these activities would be useful for an enzyme with the collular function of removing and replacing damaged parts of DNA, but seem less necessary for one concerned only with the replication of DNA.

But the demonstration that DNA polymerase has some function in vitro is no longer convincing as evidence that it does so in vivo. A surer guide would be to see what cellular properties are impaired by a mutation in the gene for DNA polymerase. Such a mutant was isolated by assaying many mutagenized elones of $E$. coli for DNA polymerase activity in vitro until one proved defective ${ }^{2 x}$; in spite of its defect, the Cairns mutant can grow normally and replicate its DNA. But it is five times more sensitive to ultraviolet light than is its parent strain, supporting the idea that in vivo DNA polymerase is concerned with the repair of damaged $D_{N A}^{22}$. It is not yet clear just which enzyme functions are impaired in the mutant, for it retains a normal ability to excise thymine dimers from its $\mathrm{DNA}^{23}$. After ultraviolet irradiation, however, the mutant degrades its DNA to a greater extent than does the wild type, in a way which suggests that this degradation is due to an exonuclease. The mutant may have a DNA polymerase, therefore, which although unable to synthesize DNA can still degrade it, but in which this latter activity has somehow been altered.

If DNA polymerase does not replicato DNA, what does ? The identification of other enzyme systems in vitro has proved difficult because the activity of DNA polymerase obscures any other DNA synthesizing activities. But two systems which lack DNA polymerase activity and can nevertheless replicate DNA have now been developed at the Max Planck Institute in Tubingen. One preparation uses a procedure in which DNA poly. merase can be washed out of the preparation ${ }^{24}$, and the other has made use of the Cairns mutant defective in the enzyme ${ }^{25}$. Both comprise membrane-protein fractions of $E$. coli which can replicate DNA semi-conservatively at a rate comparable to that prevailing in vivo (DNA polymerase works only much more slowly).

The idea that DNA replication may take place at a complex associated with the membrane of the cell first arose from evidence that the origin (where replication starts) and the growing point (the present location of the replicating enzyme(s)) of bacterial chromosomes seem to be associated with the cell membranc ${ }^{2}$. One possibility is that replication may not be catalysed by a single enzyme, such as DNA polymerase, but may instead 
take place at a replicating complex consisting of many enzymes and associated with the cell wall (much as protein synthesis is accomplished by the enzyme complex comprising the ribosome). The task of identifying individual replicating enzyme activities may prove to be very difficult if it turns out that the complex (if it exists) can function only as a whole, and cannot be analysed enzymo by enzyme.

\section{Isolation and Synthesis of Genes}

Although tho spectre of genetic engineering was raised by the isolation and synthesis of specific genes, neither of these events really marked much advance towards the prospect of new genes for old humans. The isolation by Beckwith's group at Harvard of the pure DNA carrying the genes for much of the lactose operon of $E$. coli is notable for the elegance of the experimental technique ${ }^{26}$. Essentially, this involved adding the bacterial genes to the DNA of two bacteriophages in such a way that when the corresponding single strands of the duplex DNA of the two phages were prepared, each strand carried one of the two strands of the DNA of the lactose operon. The bacteriophage strands were therefore complementary in the sequence for the lactose genes only, so that hybridization of the two sets of strands gave duplex DNA corresponding only to the bacterial operon.

The isolation of much of the lactose operon in pure form, including two of its control elements, the operator and the promotor, will be invaluable in studying the nature of the interaction between proteins (such as repressors or RNA polymerase) and DNA. How a protein can recognize a sequence of base pairs in DNA remains one of the main unsolved puzzles of molecular biology. How the activity of the lactose operon is controlled is also turning out to be rather more complicated than anyone had suspected until very recently (see Nature, 226, 1093; 1970), and a defined system to work with cannot be but useful.

But this type of approach is limited by its very nature to bacterial systems, where a bacteriophage may pick up a small and specified segment of the genetic material of its bacterial host. In lieu of any comparable system in the cells of higher organisms, there would seem to be no prospect whatsocver of extending a similar approach to them.

Khorana's synthesis at Wisconsin of the gene which codes for yeast alanine tRNA ${ }^{27}$ is perhaps as much of symbolic as of immediate practical value. The properties of the product transcribed from this gene will certainly yield some interesting information about transfer RNA. but this is not the only way to study the synthesis of tRNA. Certainly, the synthesis of a DNA sequence corresponding to a tRNA is not in itself as important as will be the future extension of the techniques which Khorana has pioneered to the synthesis of other genes, and perhaps to their linking together into polygenic pieces of DNA.

Making a geno which codes for a protein may prove to be more difficult; even the smaller proteins would demand rather larger genes-insulin, for example, would have to be coded by a gene some twice the size of that for alanine tRNA. And the ready transcription and translation of such genes is by no means assured until the nucleotide sequences of the signals for starting and stopping transcription and translation are known. The idea that the day will soon come when extra pieces of DNA can be synthesized and added at will to the genome of higher organisms to repair their defects is not only naive but also wrong-headed.

\section{Dogmas and Heresies}

The reverence with which DNA is regarded as the repository of genetic information in the nucleus has come under some attack in recent months. First came tho pro. posal that DNA is present in the eytoplasm of cells of higher organisms ${ }^{28}$, where it might fulfil functions analogous to those of messenger RNA. But this "information". DNA has now fallen by the wayside, for further experiments have shown its presence in cytoplasmic extracts to be an artefact of the preparative procedures used ${ }^{29}$.

The abrogation to RNA of some of the properties previously reserved for DNA has, however, proved rather more successful. The fastest rolling bandwagon ever seon even in molecular biology must surcly be exploitation of the discovery that RNA tumour viruses can act as templates for the synthesis of $\mathrm{DNA}^{30,31}$. Perhaps the winner of this race-if there is to be a winner-will entortain us with a counterpart to Watson's exposé in The Double Helix.

The RNA-dependent DNA polymerase contained in the virion of RNA turnour viruses seems to catalyse the synthesis of an RNA-DNA hybrid, using the RNA genome of the virus as template for the synthesis of a complementary strand of $\mathrm{DNA}^{32,33}$. So far, the extent of hybrid formation has been shown to correspond to only a small part of the viral genome, but even so, it seems probable that hybrid formation serves as a first step towards the synthesis of a duplex DNA, corresponding to at least some of the viral genes, which can bo integrated into the genome of the host cell. Other enzymes would be needed to complete this process; the virion also contains a DNA polymerase which can replicate duplex DNA and may be one of them ${ }^{34}$.

It is too early to say whether this mechanism has evolved especially to enable the genetic information coded by RNA tumour viruses to be integrated into the cell genome, or whether similar information retrieval systems exist in uninfected animal cells. If there is no countorpart in the host cell to these viral enzymes, it should prove possible to inhibit selectively the action of the virus without harming the host cell.

The ease with which this discovery has been fitied into the existing conceptual framework of molecular biology shows just how little it has really upset present ideas. There is, after all, a ready way for DNA sequences to bo derived from RNA. The synthesis of DNA from RNA templates will doubtless prove to be more useful for study of the unusual enzyme systems which reverse the normal relationship between template and product in nucleic acid synthesis than it will for the demolition of the central dogma.

Tho central dogma, enunciated by Crick, the high priest of molecular biology, has long been taken to say that the flow of genetic information from DNA through RNA to protein is a one way process which cannot be reversed. Certainly, in formal terms this idea is no longer valid. But this is of little import in more practical terms. The ultimate heresy -which would require a drastic rethinking of the whole conceptual basis of molecular biology-would be the retrieval of genetic information from protein to nucleic acid ${ }^{35}$. But of this there is no sign yet.

${ }^{1}$ Stent, G. S., Science, 160, 390 (1968).

Lewin, B. M., The Molecular Basis of Gene Expression (Wiley, London, 1970). 
S Laycock, D. G., and Hunt, J. A., Nature, 221, 1118 (1969).

- Liew, C. C., Haslett, G. W., and Allfrey, V. G., Nature, 226, 414 (1970).

5 Smith, A. E., and Marcker, K. A., Nature, 226, 607 (1970).

- Brown, J. C., and Smith, A. E., Nature, 226, 610 (1970).

'Jackson, R., and Hunter, T., Nature, 22\%, 672 (1970).

"Wigle, D. T., and Dixon, G. H., Nature, 227, 676 (1970).

'Shafritz, D. A., and Anderson, W. F., Nature, 22\%, 918 (1970).

${ }^{10}$ Steitz, J. A., Nature, 224, 957 (1969).

${ }^{11}$ Nichols, J. L., Nature, 225, 147 (1970).

2 Billeter, M. A., Dahlberg, J. E., Goodman, H. M., Hindley, J., and Weissmann, C., Nature, 224, 1083 (1969).

${ }^{13}$ Roberts, J. W., Nature, 224, 1168 (1969).

${ }^{14}$ Sugiura, M., Okamoto, T., and Takanami, M., Nature, 225, 598 (1970).

${ }^{15}$ Bautz, w. K. F., Bautz, F. A., and Dunn, J. J., Nature, 223, 1022 (1969).

${ }^{26}$ Travers, A. A., Nature, 225, 1009 (1970).

17 Kuwano, M., Schlessinger, D., and Apirion, D., Nature, 228, 514 (1970).

${ }^{18}$ Morse, D. E., and Primakoff, P., Nature, 226, 28 (1970).

"Kornberg, A., Science, 163, 1410 (1969).

${ }^{20}$ Kelley, R. B., Atkinson, M. R., Huberman, J. A., and Kornberg, A., Nature, 224, 495 (1969)

${ }^{21}$ De Lucia, P., and Cairns, J., Nature, 224, 1164 (1969).
${ }^{22}$ Gross, J., and Gross, M., Nature, 224, 1166 (1969).

23 Boyle, J. M., Paterson, M. C., and Setlow, R. B., Nature, 226, 708 (1970).

${ }^{24}$ Smith, D. W., Schaller, H. E., and Bonhoeffer, F. J., Nature, 226, 711 (1970).

${ }^{25}$ Knippers, R., and Stratling, W., Nature, 228, 713 (1970).

${ }^{26}$ Shapiro, J., Machattie, I., Eron, L., Ihler, G., Ippen, K., and Beckwith, J., Nature, 224, 768 (1969).

27 Agarwal, K. L., Buchi, H., Caruthers, M. H., Gupta, N., Khorana, H. (i. Kleppe, K., Kumar, A., Ohtsuka, E., Rajhbandary, U. L., Van de Sande, J. H., Sgaramella, V., Weber, H., and Yamada, Y., Nature, 22\% $27(1970)$.

${ }_{28}^{8}$ Bell, E., Nature, 224, 326 (1969).

${ }^{20}$ Fromson, D., and Nemer, Mr., Science, 168, 266 (1970).

${ }^{30}$ Baltimore, D., Nature, 226, 1209 (1970).

${ }^{31}$ Mizushima, S., and Temin, H., Nature, 226, 1211 (1970).

${ }^{32}$ Spiegelman, S., Burny, A., Das, M. R., Keydar, J., Schlom, J., Travuicek, M., and Watson, K., Nature, $22 \%, 563(1970)$.

${ }^{33}$ Rokutanda, M. Rokutanda, H., Green, M., Fujinaga, K., Rau, K. K., and Gurgo, C., Nature, 227, 1026 (1970). 34 Spiegelman, S., Burny, A., Das, M. R., Keydar, J., Schlom, J., Travinicek,
M., and Watson, K., Nature, 22\%, 1029 (1970).

${ }^{35}$ Crick, F., Nuture, 227, 561 (1970).

\section{The Geophysicul Year}

by

\section{F. J. VINE}

School of Environmental Sciences, University of East Anglia
During the past year the results of deep sea drilling and other geophysical investigations have continued to strengthen the concepts of sea floor spreading and plate tectonics. Samples of lunar rock, too, have focused attention again on the history of the Earth.
1969-70 has been yet another year of spectacular advance and rejuvenation within the Earth sciences, although with the advent of lunar exploration and its associated scientific programme the term Earth sciences is something of a misnomer. The profession is buoyed up not only by the return of rock samples from the Moon and the ability to carry out physical experiments and observations on the lunar surface, but also by a plethora of results from the successful deep sea drilling programme, and the insight being gained into all aspects of geology through the pursuit of the unified concepts of sea floor spreading, plate tectonics and continental drift.

The concept of sea floor spreading was essentially a phenomenon of the $1960 \mathrm{~s}$; formulated by the late $\mathrm{H}$. $\mathrm{H}$. Hess of Princeton in 1960 and finally confirmed beyond reasonable doubt by the results of the first phase of the JOIDES deep sea drilling project in 1969. This single, revolutionary and elegant hypothesis simultaneously revived the older, but largely rejected, concept of continental drift and paved the way for the more modern and even more potent concept of plate tectonics.

Briefly, Hess ${ }^{1}$ postulated that, as a result of convection in the Earth's mantle, the deep ocean basins are young and ephemeral features of the Earth's surface, constantly being regenerated at mid-ocean ridge crests, which are situated over mantle upwellings, and destroyed beneath the marginal trenches and. island ares which are the "sinks" in the system (Fig. 1). If such an upwelling were initiated beneath a continental area, the continent would be rifted and "drifted" apart and an intervening ocean basin formed as a result of lateral and symmetrical accretion of new ocean floor to the rift flanks; the rift ultimately becoming a mid-ocean ridge crest. The Atlantic and Indian Oceans might have been formed in this way during the past 200 million years, resulting in the separation of the surrounding continents, and implying average rates of lateral accretion or "spreading" of the ocean floor of $1-2 \mathrm{~cm} / \mathrm{yr}$. The East Pacific Rise might also be a spreading ridge but initiated within a former oceanic area and therefore not constrained to be in a median position within the P\&cific Ocean basin.

\section{Magnetic Anomalies give Time Scale}

In 1963, Matthews and I suggested ${ }^{2}$ that sea floor spreading might be recorded in terms of the disturbances or "anomalies" in the Earth's magnetic field recordcd over the ocean basins. If the Earth's magnetic field has reversed its polarity in the past then such reversals, coupled with spreading, would prcduce "avenues" of normally and reversely magnetized crust parallel to and symmetrically disposed about the mid-ocean ridge crests. The magnetization contrasts between these avenues would be capable of producing appreciable disturbances in the magnetic field at or above sea-level as measured by a ship or aircraft. By 1966 a geomagnetic reversal time scale had been deduced empirically for the past 3.5 million years from detailed palaeomagnetic and dating studies of subaerial lava flows and deep sea sediment cores. With the definition of this reversal time scale it was possible to demonstrate that the magnetic anomalies associated with ridge crests can be explained in terms of symmetrical spreading at essentially constant rates during the past 3.5 million years ${ }^{3}$. The distance from the ridge axis at which particular reversals are recorded makes it possible to deduce rates of spreading for all ridge crests for which magnetic data are available. Rates deduced in this way are indicated in Fig. 2 by the separation of the pair of solid lines adjacent to the dotted lines at the ridge crest. Integrated along the whole length of the midocean ridge system these rates imply the formation of new oceanic crust at a rate of $2 \cdot 6 \pm 0 \cdot 2 \mathrm{~km}^{2} /$ year (ref. 4).

The technicalities of both lava flow and sediment methods for determining the age of geomagnetic reversals are such that neither can extend the time scale back beyond 3.5 million years very readily or precisely. But the same sequence of magnetic anomalies away from ridge 